\title{
Student-informed directives for clinical communication skills training in undergraduate healthcare programmes: Perspectives from a South African university
}

\author{
E C Janse van Vuuren, ${ }^{1} \mathrm{PhD} ; \mathbf{M ~ N e l}^{2}{ }^{2} \mathrm{MMedSc}$ \\ ${ }^{1}$ Department of Physiotherapy, Faculty of Health Sciences, University of the Free State, Bloemfontein, South Africa \\ ${ }^{2}$ Department of Biostatistics, Faculty of Health Sciences, University of the Free State, Bloemfontein, South Africa
}

Corresponding author: E C Janse van Vuuren (jansevanvuurenec@ufs.ac.za)

\begin{abstract}
Background. Clinical communication skills (CCS) are fundamental to good-quality healthcare and health outcomes, but remain problematic for healthcare students - in particular in the multilingual, multicultural South African context. As CCS can be taught, the importance of CCS training in healthcare programmes, as the basis of clinical practice, is well known.

Objectives. To suggest practical, student-informed directives for CCS training, we explored current challenges of undergraduate healthcare students and their CCS training.

Methods. The research was conducted in two phases. A mixed-methods approach was followed in phase 1, including a questionnaire survey ( $n=38)$ and semi-structured interviews ( $n=19)$, among third-year physiotherapy students. A quantitative questionnaire survey was conducted in phase 2 among final-year allied healthcare students $(n=105)$.

Results. Results from phase 1 indicated that students found it difficult to communicate with other members of the healthcare team (64\%) and with patients' families (82\%). Students indicated that language barriers influenced their treatment of patients negatively. In phase 2 of the research, only $43 \%$ of students indicated previous exposure to CCS training, and they supported the inclusion of specific CCS training methods throughout their undergraduate education.

Conclusions. CCS training directives, which are specifically focused on patient, family, interdisciplinary and written communication and enhancement of the student voice in the training, are suggested for inclusion in undergraduate healthcare programmes.
\end{abstract}

Afr J Health Professions Educ 2018;10(4):199-204. DOI:10.7196/AJHPE.2018.v10i4.1009

Clinical communication skills (CCS) are core to the successful practice of healthcare professionals, as good CCS are directly linked to positive patient health outcomes and satisfaction of patients with their care. ${ }^{[1]}$ In the past, it was thought that CCS cannot be taught, but the literature indicates that it can indeed be taught and developed by specific, focused teaching and learning activities. ${ }^{[1]}$ Rotthoff et al. ${ }^{[2]}$ point out that clinical experience does not automatically improve CCS and that the training thereof is essential and should be ongoing. ${ }^{[2]}$ Attentive consideration of relevant CCS training is therefore essential if adequately trained healthcare professionals are to be delivered.

Various aspects are included under the domain of CCS, such as empathy, listening skills, ${ }^{[3]}$ ability to convey information and give constructive feedback, body language and documenting health information. ${ }^{[4]}$ The literature describes a wide variety of methods that are used to teach and enhance CCS in healthcare students, including theory-based, practicebased and clinical-based methods. However, Parry and Brown ${ }^{[5]}$ found that theoretical instruction is still the major method for CCS training, which results in limited translation into the clinical setting. Junod Perron et al. ${ }^{[6]}$ warn that a longitudinal decrease of CCS could occur if skills are not practised constantly. Wouda and Van de Wiel ${ }^{[7]}$ suggest that CCS training should be a continuous 'mainstream activity' to develop students' CCS to an expert level.
Strategies for training of CCS in healthcare programmes include role-play, video playback, audio-visual aids (such as videos), simulated/standardised patients, clinical training, peer evaluation and group discussions/activities. ${ }^{[1]}$ Thoughtful integration of a variety of methods can create a balance between theoretical, practical and clinical strategies, which should be carefully selected, planned and integrated in healthcare training programmes, if the desired outcomes for CCS are to be attained. The assessment and feedback strategies associated with the use of each of the CCS training activities should also be planned carefully to enhance learning. Lanning et al.$^{[8]}$ regard a combination of peer, self, student instructor (tutor) and lecturer (academic) assessments and/or feedback strategies to be potentially appropriate to achieve the desired outcomes.

In addition to the attainment of the basic CCS mentioned, many barriers, such as culture and language, further restrict the communication-related performance of healthcare students within the clinical environment. Schyve, ${ }^{[9]}$ for example, alludes to patient populations worldwide becoming more multicultural and multilingual - a phenomenon that complicates communication further. The importance of unceasing changes in the healthcare environment, and the impact thereof on healthcare delivery (and training), is highlighted by the ongoing debate regarding cultural and language competence and their influence on communication (and CCS training) within the healthcare setting. ${ }^{[10]}$ 
The first author, a physiotherapy lecturer at a South African (SA) university for $>15$ years, recognised continuing challenges associated with CCS among physiotherapy students during their clinical training. Scrutiny of previous research into CCS training appeared to be focused predominantly on the educator voice and the testing of different CCS training methods, portraying a rather limited reference to the student voice. This apparent shortcoming in the literature, as well as the authors' concerns relating to the performance of their students, served as an impetus for undertaking this study. This article should therefore be regarded as a contribution to the CCS knowledge base by providing a student perspective on CCS training by exploring their experiences, expectations and possible suggestions for more effective CCS training at undergraduate levels.

\section{Methods}

The research was conducted in two independent phases. The first phase consisted of an explanatory, sequential, mixed-methods approach, as described by Creswell. ${ }^{[11]}$ In this phase, results from an initial questionnaire survey served as the basis for the development of an interview schedule for the qualitative section of the phase. A descriptive, quantitative study was undertaken in the second phase of the research.

The questionnaires used in both phases of the study were self-compiled and informed by the relevant literature. These were made available in both instructional languages (i.e. English and Afrikaans) at the University of the Free State (UFS), Bloemfontein, SA, at the time of the research. Backtranslation was used to ensure comparability of the English and Afrikaans questionnaires. To enhance the validity, both questionnaires were compiled from the relevant literature and reviewed by experts in the field of physiotherapy and physiotherapy education to ensure appropriateness and perspective reflection. Reliability was addressed by means of pilot studies conducted for both phases of the study, during which participants could provide feedback on the questionnaires tested. Details of the pilot studies are included in Table 1. Trustworthiness, for the qualitative section of the study, was enhanced by the verbatim transcription of recorded interviews by an independent transcriber, which ensured truth value of the data, as the data could be revisited.

\section{Ethical approval}

Participation in both phases was voluntary. The two phases of the study were approved separately by the Ethics Committee of the Faculty of Health
Sciences, UFS (ECUFS ref. no. 78/2011 and ECUFS ref. no. 79/2012, respectively). Valuable results obtained during phase 1 initiated the planning and implementation of phase 2 , which necessitated separate ethical approval.

\section{Phase 1}

The questionnaire consisted of 70 open-ended and closed-ended questions that focused mainly on communication with patients, their families and members of the interdisciplinary team, and written communication. A description of the content focus of the questionnaire is included in Fig. 1.

All third-year physiotherapy students at UFS who had engaged in clinical practice for the first

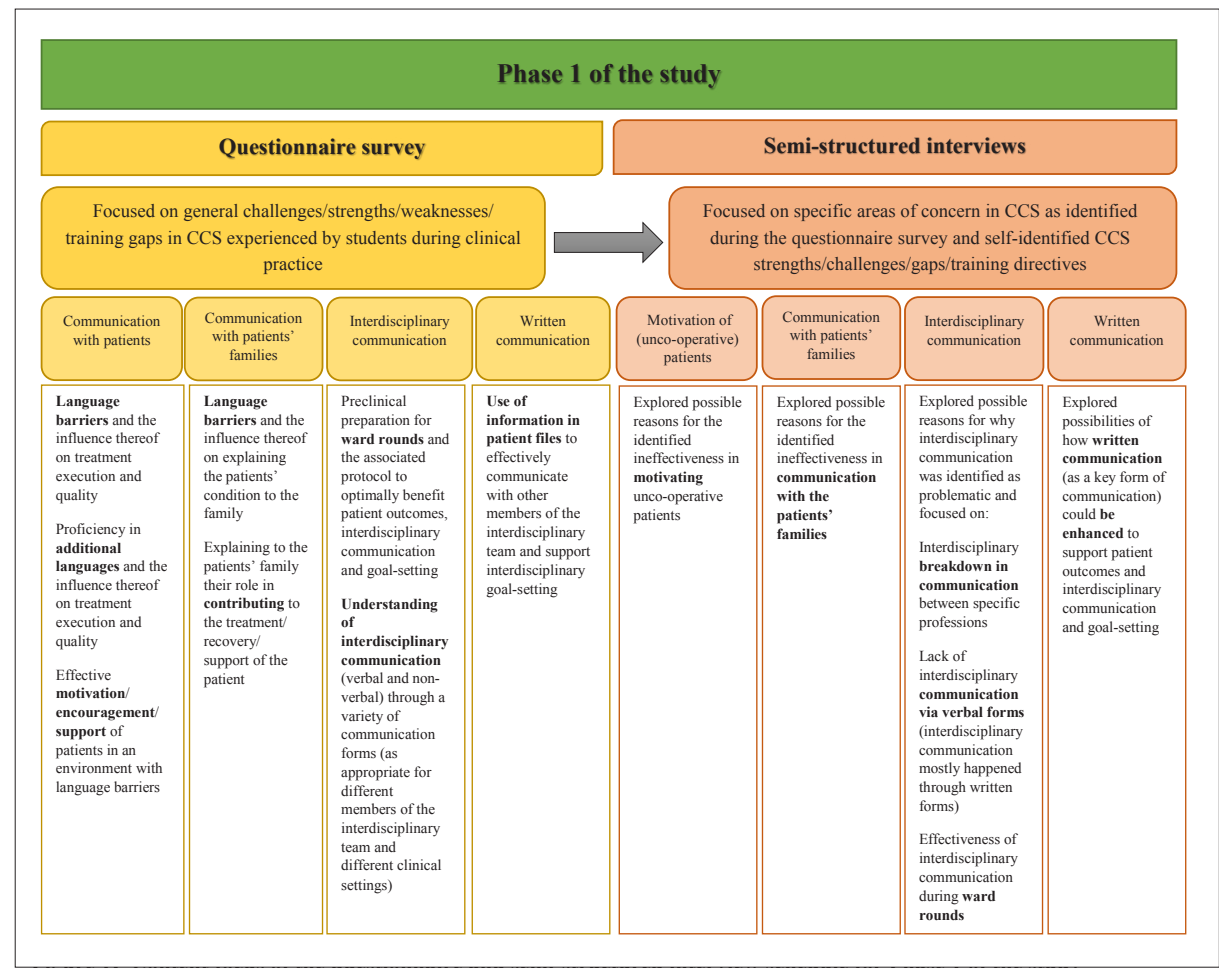

Fig. 1. Content focus of the questionnaire and semi-structured interview schedule for phase 1 of the study. (CCS = clinical communication skills.)

Table 1. Details on pilot studies for phases 1 and 2 of the study

\begin{tabular}{|c|c|c|c|}
\hline \multirow[b]{2}{*}{ Details } & \multicolumn{2}{|c|}{ Phase 1} & \multirow{2}{*}{$\frac{\text { Phase 2 }}{\text { Questionnaire survey, } n=5}$} \\
\hline & Questionaire survey, $n=10$ & Semi-structured interviews, $n=4$ & \\
\hline Sample & $\begin{array}{l}\text { Randomly selected fourth-year } \\
\text { physiotherapy students (i.e. not part of } \\
\text { the study population) }\end{array}$ & $\begin{array}{l}\text { Randomly selected from study } \\
\text { population (i.e. third-year physiotherapy } \\
\text { students) }\end{array}$ & $\begin{array}{l}\text { Randomly selected from study } \\
\text { population to represent all } \\
\text { departments included in phase } 2\end{array}$ \\
\hline Changes made after pilot study & No changes made to the questionnaire & $\begin{array}{l}\text { No changes made to the semi-structured } \\
\text { interview schedule }\end{array}$ & $\begin{array}{l}\text { Only grammatical corrections made to } \\
\text { the questionnaire }\end{array}$ \\
\hline $\begin{array}{l}\text { Data from pilot study included } \\
\text { in study data }\end{array}$ & No & Yes & Yes \\
\hline
\end{tabular}


time that year were included in the study sample $(n=38)$. Physiotherapy students were included in phase 1 of the study as a convenience sample from the same department as the first author. However, because of the value of data collected during this phase, the study was extended to all allied healthcare students in phase 2 .

Quantitative data for phase 1 were collected by the researchers during a single, pre-set session. Completed questionnaires were placed in a sealed box at the exit of the venue to ensure anonymity. The authors acknowledge that this is a relatively small number of students, but results are used to provide an indication of trends and not for generalisation.

Descriptive statistics were calculated for the quantitative data, i.e. frequencies and percentages for categorical data and medians and percentiles for continuous data, while responses from the open-ended questions were coded and reported on descriptively.

Based on the data from the questionnaire survey, a semi-structured interview schedule was developed to gain a greater in-depth view of the perceptions of these students with regard to their CCS. It included questions related to communication with specific members of the interdisciplinary healthcare team, patients' families, unco-operative patients, as well as communication during ward rounds and via patient files (Fig. 1). The interviews ended with a broader question, exploring students' perceptions of their own CCS (including strengths and weaknesses).

Nineteen participants were purposefully selected for the interview from the group who had completed the questionnaire. Participants were selected according to predetermined criteria (i.e. age, instructional language and gender) in an effort to represent variation in the study sample. The researchers conducted the interview in a single, pre-set session to limit contamination of results.

The qualitative data from the semi-structured interviews comprised verbatim transcriptions of the voice recordings. The researchers used inductive coding ${ }^{[12]}$ to analyse the transcribed data, which were read repeatedly, and descriptive codes were assigned to data bits. These codes were continuously refined and revised as relevant data were put together. The researchers then read through the codes, identifying recurrent themes, which became the categories. Lastly, these categories were combined with quantitative data to formulate the training directives for CCS training presented in this article. There was a high level of agreement between the emergent categories and the focus of the questionnaires (i.e. language barriers, family communication, interdisciplinary communication and written communication). Interestingly, patient communication did not emerge as a specific category in the qualitative section of the study, possibly as participants were mostly satisfied with their communication skills with patients (Table 2).

\section{Phase 2}

Phase 2 of the research made use of a descriptive, quantitative study to determine the theoretical, practical and clinical methods for CCS training employed by allied healthcare training programmes. Students could rate and reflect on their experience of CCS training, as well as the strategies to be introduced in their respective training programmes to enhance their CCS training. Fig. 2 displays a description of the content focus of the questionnaire.

Phase 2 included 105 final-year allied healthcare students (from the departments of physiotherapy, occupational therapy, optometry, dietetics and nutrition). The questionnaire was completed in a computer laboratory during a single, pre-set session per department (and within 1 week for all departments to limit contamination). As students might not have been familiar with all the training methods referred to in the questionnaire, preloaded videos and a glossary explaining each of the methods were made available during the administration of the questionnaire. The preloaded videos were available on each of the computers in the computer laboratory for participants to access during completion of the questionnaire, as

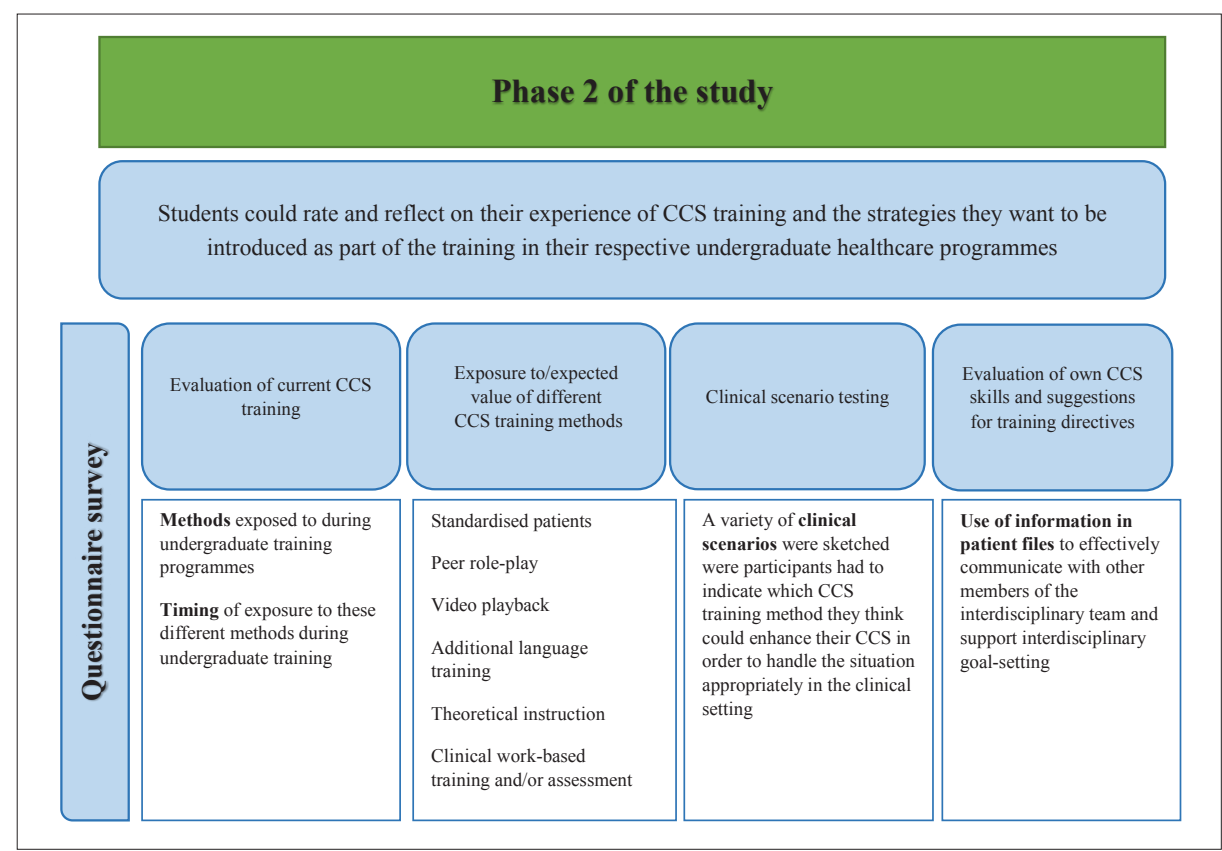

Fig. 2. Content focus of the questionnaire for phase 2 of the study. (CCS = clinical communication skills.)

Table 2. Confidence in communication with patients in the clinical setting $(n=35)$

\begin{tabular}{lll}
\hline Communication & Yes, \% & No, \% \\
\hline In general, do you find it easy to communicate with your patients? & 79 & 21 \\
Do you feel you could effectively explain your treatment to your patient in layman's terms? & 77 & 23 \\
Could you correct your patients if they were carrying out a technique incorrectly? & 94 & 6 \\
Could you effectively motivate your patients if they were struggling with their condition or feeling depressed? & 74 & 26 \\
If the patient did not understand the implications or prognosis of his condition, could you assist him with these aspects? & 80 & 20
\end{tabular}


needed. Completed questionnaires were placed in a sealed box at the exit of the venue to ensure anonymity.

Descriptive statistics were calculated, i.e. frequencies and percentages for categorical data and medians and ranges for continuous data (as the distribution of age was skew).

\section{Results and discussion}

Demographic data indicate that 35 physiotherapy students participated in phase 1 of the study, giving a response rate of $92 \%(n=38)$. The median age of the participants was 21 (range $20-31)$ years, and $65.7 \%(n=35)$ were women. For phase 2, the study population included 105 allied healthcare students, of whom 67 participated in the questionnaire survey (response rate 63.8\%). The median age of the participants was 22 (range 21 - 27) years and the majority of participants (85\%) were women. All departments training allied healthcare students were represented (Table 3 ).

Even though comprehensive data were gathered during the two phases of the study, results in the remainder of the discussion reflect only on key aspects and patterns of meaning that were identified, and which were used to derive a number of practical directives for CCS training in the specific context.

\section{Students' perspectives on clinical communication skills within the clinical setting (phase 1)}

Quantitative data with regard to communication with patients showed overall confidence among participants (Table 2).

Despite these positive findings, all participants $(n=35)$ indicated that language differences sometimes negatively influenced the effectiveness of their treatments, which can be expected in a multilingual country such as SA. This conclusion was confirmed by several interview responses in the category language barriers, e.g. that 'sometimes they [patients] don't understand you because they speak another language and you don't always get the message through to them' [translated]. This corresponds to results of a study by Bischoff and Denhaerynck, ${ }^{[13]}$ which found that language barriers often diminish health outcomes. It has been suggested that instruction in the basics of an additional language to healthcare professionals and students could improve quality of care, patient satisfaction, and level of communication between patients and healthcare professionals, as well as decrease misunderstandings and frustration. ${ }^{[14]}$ In support of this suggestion, $97 \%$ of participants in phase 1 indicated that basic education in an additional language would benefit their patient interactions; it is included as part of the CCS training directives (Fig. 3).

Communication with patients' families was found to be problematic by $82 \%$ of participants $(n=35)$, mostly because family members were not present when treatment was administered. This finding was confirmed by the interviews and responses were included in the category family communication, such as: 'I think it is difficult to communicate with the family in the set-up in which we work, which is mainly in the mornings and not during visiting hours' [translated]. Wolff ${ }^{[15]}$ and Ahmann and Dokken ${ }^{[16]}$ refer to the importance of involving patients' families in their care to improve the partnership between healthcare professionals and the family, and quality of healthcare provided. Communication with the families of patients is therefore specifically included in the CCS training directives (Fig. 3).

Communication within the interdisciplinary healthcare team was another key area of concern for $64 \%$ of survey participants $(n=35)$. Reasons included a lack of understanding of the roles of other healthcare professionals in the healthcare team and communication breakdown, mostly due to time or availability constraints. These results were supported by qualitative interview responses in the category interdisciplinary communication, such as 'they don't really know the clinical presentation of the patients and how it influences us', and 'often you phone them and then they are busy, hurried and you feel in the way' [translated]. Weller et al. ${ }^{[17]}$ as well as Nancarrow et al. ${ }^{[18]}$ identified understanding the roles within the interdisciplinary team and specific communication strategies as key components of effective interdisciplinary communication and teamwork. This forms the basis of CCS training

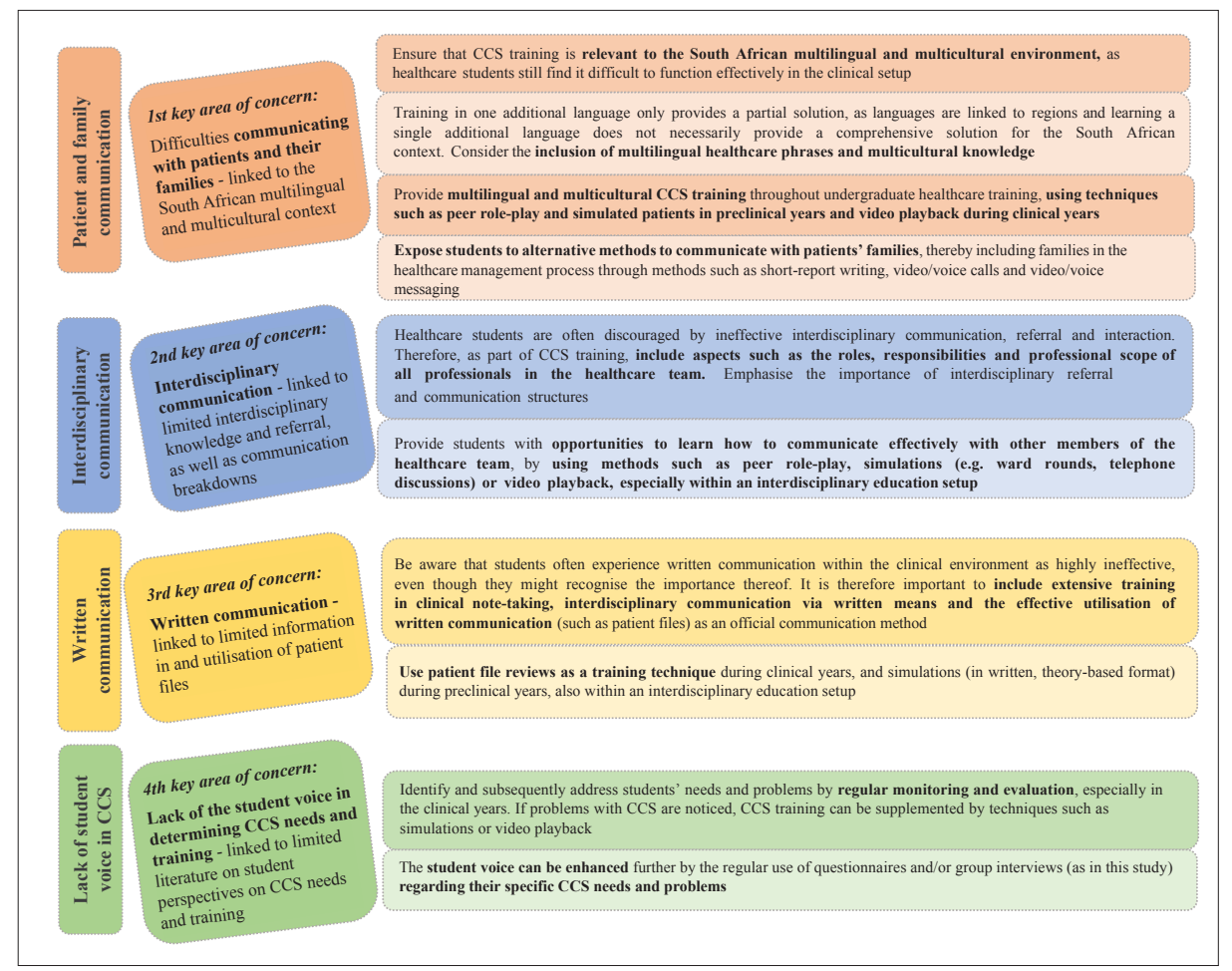

Fig. 3. CCS training directives for undergraduate healthcare programmes. (CCS = clinical communication skills.)

Table 3. Departmental representation of study population and study sample for phase 2 of the study

\begin{tabular}{lllll}
\hline Study population or sample & Physiotherapy & Occupational therapy & Dietetics and nutrition & Optometry \\
\hline Study population, $n$ & 30 & 35 & 14 & 18 \\
Study sample, $n$ (response rate, \%) & $30(100)$ & $16(45.7)$ & $7(50)$ & $14(77.8)$
\end{tabular}


directives related to interdisciplinary communication (Fig. 3). Nevertheless, the participants mostly had a positive perception of communication with professionals from their own discipline. The majority of participants (65-92\% in different clinical settings; $n=35$ ) indicated that they discussed treatment plans with qualified healthcare professionals. The qualitative responses, included in the category for interdisciplinary communication, reflected the same message and included responses such as: 'I really felt I could talk to each one of them and ask questions' [translated] and 'the best part was that they were prepared to teach us' [translated]. Some participants held other views, however, and stated that 'there were a few qualified physiotherapists that were not very friendly. They left us in the deep end.' Powell and Toms ${ }^{[19]}$ emphasised the importance of good communication platforms and qualified personnel to serve as role models to healthcare students in training, as it creates an effective learning environment.

Written communication was seen as another problematic area in this study, as only $34.3 \%$ of respondents $(n=35)$ stated that patient files contained sufficient information. Only $40 \%(n=35)$ indicated that their notes were used by other members of the interdisciplinary healthcare team, even though the majority of participants indicated that most of the communication within the interdisciplinary team was based on notes in patient files $(57-80 \%$ in different clinical settings). The interviews supported these results, included in the category of written communication, by responses, such as: 'I feel it [patient files] is a good way to communicate but then everybody has to write on the same page' [translated]. According to Pullen and Loudon, ${ }^{[20]}$ effective patient record-keeping is very important for effective interdisciplinary communication, but records are often poorly maintained and not prioritised by members of the healthcare team. Written communication forms an important component of CCS training directives (Fig. 3).

\section{Students' perspectives on current clinical communication skills training (phase 2)}

Less than half of the participants (43.3\%) indicated that they had been exposed to any methods to improve their CCS during their current training programmes (Table 4).

Participants who indicated previous exposure to CCS training reported that $\sim 29 \%$ of the training opportunities were theory based, $19 \%$ practice based and $52 \%$ clinically based. Theoretical training opportunities included lectures, written notes, e-presentations (computer based) and readers on basic communication and communication skills, communication via different media formats, importance of effective communication practices, psychology of empathy and non-verbal communication, as well as applicable Sesotho [local language] words and phrases. Practical training opportunities included peer role-play and practice opportunities with peers, demonstrations and group discussions. Lastly, the clinical techniques included real-life communication with patients, their families and other members of the healthcare team, and clinical attendances, such as ward rounds and non-verbal communication via medical records, using the services of an interpreter and community-based learning.

Simulated patients, peer role-play and video playback have been identified as practical methods to improve CCS in undergraduate healthcare students. Table 4 gives an indication of the participants' knowledge, current use and anticipated value for implementing these methods.

Participants with previous exposure to the abovementioned practical methods of CCS training indicated that simulated patients and video playback were used during their third year of study, while peer role-play was used in both the second and third years of study. Most of the participants $(82.8 \% ; n=67)$ thought that using these methods benefited them personally, and indicated that specific CCS training methods could also benefit other students if included in their undergraduate training programmes (Table 5). Participants ( $n=67)$ were mostly in favour of peer role-play $(87 \%)$ and simulated patients (80\%) being implemented in their undergraduate training programme in the year(s) preceding clinical engagement with patients, while video playback (78\%) was preferred during the first year of clinical engagement (as an opportunity to reflect on their own CCS during real-life clinical encounters). These methods are specifically included in the CCS training directives proposed in this article (Fig. 3).

\section{Student-informed clinical communication skills training directives}

The integration of key findings from both phases of this study - emphasising the student voice in an SA context - informed the formulation of a number of practical CCS training directives for undergraduate healthcare programmes (Fig. 3).

Fig. 3 firstly presents the problems students experienced with CCS, as mentioned during phase 1 of the study. These involved four main areas, i.e. patient and patient family communication, interdisciplinary communication, written communication and absence of the student voice in CCS training. To address the abovementioned problems effectively, either in isolation or in different combinations, training directives included in Fig. 3 build on results from phase 2 , and include suggestions for training methods that could be incorporated in undergraduate healthcare programmes to teach CCS.

The value of the research, therefore, lies on practical and theoretical levels, and provides a unique student perspective. A concern noticed from the student perspective, is the participants' lack of understanding or acknowledgement of CCS training included in their undergraduate training

Table 4. Knowledge, current use and anticipated value of simulated patients, peer role-play and video playback as methods to improve clinical communication skills in undergraduate healthcare programmes $(n=67)$

\begin{tabular}{|c|c|c|c|c|c|c|c|}
\hline \multirow[b]{2}{*}{ Training method } & \multirow[b]{2}{*}{$\begin{array}{l}\text { Knowledge of } \\
\text { the method,\% }\end{array}$} & \multirow[b]{2}{*}{$\begin{array}{l}\text { Current use of } \\
\text { the method, \% }\end{array}$} & \multicolumn{5}{|c|}{$\begin{array}{l}\text { Anticipated value of implementing the method to } \\
\text { improve different aspects of clinical communication skills }\end{array}$} \\
\hline & & & $\begin{array}{l}\text { Written } \\
\text { communication, \% }\end{array}$ & $\begin{array}{l}\text { Non-verbal } \\
\text { communication, \% }\end{array}$ & $\begin{array}{l}\text { Verbal } \\
\text { communication } \\
\text { with patients, \% }\end{array}$ & $\begin{array}{l}\text { Verbal } \\
\text { communication } \\
\text { with patients' } \\
\text { families, \% }\end{array}$ & $\begin{array}{l}\text { Interdisciplinary } \\
\text { communication, \% }\end{array}$ \\
\hline Simulated patients & 32.8 & 32.8 & 46.9 & 77.3 & 95.5 & 68.2 & 59.1 \\
\hline Peer role-play & 56.7 & 50.8 & 33.9 & 66.1 & 93.2 & 67.8 & 67.8 \\
\hline Video playback & 55.2 & 30.3 & 24.2 & 83.3 & 92.4 & 75.8 & 74.2 \\
\hline
\end{tabular}


Table 5. Previous exposure to methods to improve clinical communication skills per undergraduate healthcare programme

\begin{tabular}{lll}
\hline Department & Yes, $\boldsymbol{n}$ (\%) & No, $\boldsymbol{n}$ (\%) \\
\hline Physiotherapy $(n=30)$ & $11(36.7)$ & $19(63.3)$ \\
Occupational therapy $(n=16)$ & $11(68.8)$ & $5(31.2)$ \\
Dietetics and nutrition $(n=7)$ & $5(71.4)$ & $2(28.6)$ \\
Optometry $(n=14)$ & $2(14.3)$ & $12(85.7)$
\end{tabular}

programmes (Table 5). Questions could be raised regarding curriculum design and emphasis on CCS in the curriculum, or the possible lack of students' understanding of CCS. To address these concerns, the directives, as provided in this article, can serve as a guide to healthcare educators on aspects such as curriculum design and inclusion of teaching and learning activities and assessment tasks specifically related to CCS. Adaptations to the use of simulation, peer role-play and video playback for enhancing the practical training of the necessary CCS, specifically, and the importance thereof for enhancing inadequate CCS identified in the clinical setting, are important study contributions (Fig. 3). Another key directive proposed as a result of this study, is teaching students healthcare phrases in several languages, instead of training in a single additional language, owing to the limitations posed by a single language in a wide geographical area (Fig. 3).

\section{Conclusion}

As a result of student perspectives gained, this article proposes CCS training directives for the SA multilingual and multicultural environment, which could be considered for implementation in similar contexts, or customised for other contexts.

The findings and proposed directives can also inform debate on aspects of CCS training in SA, with its particular problems and challenges. The directives lend themselves to further research and extension to include other problem areas in verbal and written CCS of healthcare students, as well as aspects directly influencing each of the problem areas. Additional research could provide evidence for the inclusion of another domain, i.e. non-verbal CCS and its related facets. The proposed directives emphasise the sentiment of Rotthoff et al..$^{[2]}$ that clinical experience does not automatically improve CCS, and training in CCS is therefore essential and should be ongoing. Attentive consideration of relevant CCS training is thus essential for delivery of adequately trained healthcare professionals.
Declaration. None.

Acknowledgements. E Colyn, De V Koster, Y Marx, N Mienie, J Oosthuizen, F de Klerk, C Engelbrecht, M Janse van Rensburg, L Opperman and Z Prinsloo collected data in 2012 and 2013 as part of their undergraduate research projects. $\mathrm{H} \mathrm{Nel} \mathrm{was} \mathrm{the} \mathrm{co-supervisor} \mathrm{of} \mathrm{the} \mathrm{undergraduate} \mathrm{research} \mathrm{project} \mathrm{conducted}$ in 2013. K Bodenstein provided valuable advice during the writing of the article. Author contributions. ECJvV wrote the article with the assistance and advice of MN. MN analysed the quantitative data and $\mathrm{ECJvV}$ the qualitative data. Both authors made significant contributions to all phases of the article, including the conceptualisation, drafting, revision and submission.

Funding. None.

Conflicts of interest. None.

1. Jarvis R, Snadden D, Ker J. Clinical communication. In: Dent J, Harden RM, eds. A Practical Guide for Medical Teachers. London: Elsevier, 2009:265-273.

2. Rotthoff T, Baehring T, David D, et al. The value of training in communication skills for continuing medical education. Patient Educ Couns 2011;84(2):170-175. https://doi.org/10.1016/.jpec.2010.07.034

3. Henry S, Fuhrel-Forbis A, Rogers M, Egoly S. Association between nonverbal communication during clinical . interactions and outcomes: A syst 4. Joseph C, Frantz JM, Hendricks C, Smith M. Evaluation of a new clinical perfor
study. S Afr J Physiother 2012;68(3):15-19. https://doi.org/10.4102/sajp.v68i3.19

study. S Afr J Physiother 2012;68(3):15-19. https://doi.org/10.4102/sajp.v68i3.19 5. Parry RH, Brown K. Teaching and learning communication skills in physiotherapy: What
be done? Physiotherapy 2009;95(4):294-301. https://doi.org/10.1016/j.physio.2009.05.003

6. Junod Perron N, Sommer J, Louis-Simonet M, Nendaz M. Teaching communication skills: Beyond wishfu thinking. Swiss Med Wkly 2015;145:w14064. https://doi.org/10.4414/smw.2015.14064

7. Wouda JC, van de Wiel HBM. The communication competency of medical students, residents and consultants. Patient Educ Couns 2012;86(1):57-62. https://doi.org/10.1016/j.pec.2011.03.011

8. Lanning SK, Brickhouse TH, Gunsolley JC, Ranson SL, Willett RM. Communication skills instruction: An analysis of self, peer-group, student instructors and faculty assessment. Patient Educ Couns 2011;83(2):145-151. https://doi org/10.1016/j.pec.2010.06.024

9. Schyve PM. Language differences as a barrier to quality and safety in health care: The joint commission perspective. J Gen Intern Med 2007;22(Suppl 2):360-361. https://doi.org/10.1007/s11606-007-0365-3

10. Burch V. Cultural competence or speaking the patient's language? BMC Health Serv Res 2010;8(1):3. https://doi org/10.7196/ajhpe competence or

1. Creswell JW. A Concise Introduction to Mixed Methods Research. Los Angeles: Sage, 2015.

11. Creswell JW. A Concise Introduction to Mixed Methods Research. Los Angeles: Sage, 2015.
12. Nieuwenhuis J. Analysing qualitative data. In: Maree K, ed. First Steps in Research. Pretoria: Van Schaik, 2016:103-131.

12. Nieuwenhuis J. Analysing qualitative data. In: Maree K, ed. First Steps in Research. Pretoria: Van Schaik, 2016:103-131.
13. Bischoff A, Denhaerynck K. What do language barriers cost? An exploratory study among asylum seekers in Bischoff A, Denhaerynck K. What do language barriers cost? An exploratory study among asy
Switzerland. BMC Health Serv Res 2010;10(1):248. https://doi.org/10.1186/1472-6963-10-248

14. Levin ME. Language and cultural competency training in South Africa: Effects on quality of care and health care worker satisfaction. Afr J Health Professions Educ 2011;3(1):11-14.

5. Wolff JL. Family matters in health care delivery. JAMA 2012;308(15):1529-1530. https://doi.org/10.1001/ jama.2012.13366

6. Ahmann E, Dokken D. Strategies for encouraging patient/family member partnerships with the health care tean. Fam Matters 2012;38(4):232

17. Weller J, Boyd M, Cumin D. Teams, tribes and patient safety: Overcoming barriers to effective teamwork in healthcare. Postgrad Med J 2014;90(1061):149-154

18. Nancarrow SA, Booth A, Ariss S, Smith T, Enderby P, Roots A. Ten principles of good interdisciplinary team work. Hum Resour Health 2013;11(1):19. https://doi.org/10.1186/1478-4491-11-19

19. Powell S, Toms J. Passing away: An exploratory study into physiotherapy students' experiences of patient death

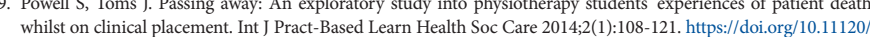
whilst on clinical

20. Pullen I, Loudon J. Improving standards in clinical record-keeping. Adv Psychiatr Treat 2006;12(4):280-286 https://doi.org/10.1192/apt.12.4.280

Accepted 5 March 2018 